\title{
POTENT INHIBITION OF Peperomia pellucida EXTRACTS TOWARDS RANKL-INDUCED OSTEOCLAST FORMATION THROUGH M1 MACROPHAGE POLARIZATION
}

\section{I.G.A.A. Kartika ${ }^{1,2}$, C. Riani $^{3}$, M. Insanu ${ }^{4}$, K. Paiboonsukwong ${ }^{5}$, N. Charoenphandhu ${ }^{5}$, A. Tubsuwan ${ }^{5}$ and I.K. Adnyana, ${ }^{1, 凶}$}

${ }^{1}$ Department of Pharmacology and Clinical Pharmacy, School of Pharmacy, Institut Teknologi Bandung, Ganesha 10 Bandung, 40132, Indonesia

${ }^{2}$ Yoga and Health Study Program, Faculty of Brahma Widya, Universitas Hindu Negeri I Gusti Bagus Sugriwa, Ratna 51 Denpasar, 80237, Indonesia

${ }^{3}$ Pharmaceutical Biotechnology Laboratory, School of Pharmacy, Institut Teknologi Bandung, Ganesha 10 Bandung, 40132, Indonesia

${ }^{4}$ Department of Pharmaceutical Biology, School of Pharmacy, Institut Teknologi Bandung, Ganesha 10 Bandung, 40132, Indonesia

${ }^{5}$ Institute of Molecular Biosciences, Mahidol University, Nakhon Pathom, 73170, Thailand

${ }^{\square}$ Corresponding Author: ketut@fa.itb.ac.id

\begin{abstract}
Osteoporosis is one of the major health problems, especially considering geriatric populations. Nowadays, the finding of an effective and cost-efficient drug from natural medicines has been conducting. One of the strong candidates is Peperomia pellucida. Aqueous and ethanol extracts of this plant have been shown to accelerate bone healing events in vivo. However, there is no data regarding the comparison of effect from its various extracts directly on bone-related cells. The aims of this study are to observe the effect of four types of extracts with different polarity from P. pellucida on the culture of bone-related cells. Effect of the extracts on the proliferation of osteoblast cells and inhibition to osteoclastogenesis were performed in UMR-106 and RAW 264.7 cells respectively, which is induced by receptor activator of NF-kappaB ligand then analyses with TRAP Staining Assay. The determination of phytochemical compounds was performed using HPLC. The extracts can decrease the viability of both cells at a concentration $100 \mu \mathrm{g} / \mathrm{mL}$. Water extract caused the morphology change of RAW 264.7 cells into M1 macrophage. No increase in osteoblast proliferation was observed. Meanwhile, each extract showed a different effect on osteoclastogenesis. Water extract successfully inhibits osteoclast formation. The activity was $92.45 \pm 1.82 \%$ at a concentration of $10 \mu \mathrm{g} / \mathrm{mL}$. The induction of macrophage M1 polarization was suggested as a mechanism of action. Apigenin was detected present in the extract by HPLC analysis. This study suggested the potential usage of water extract of $P$. pellucida as an alternative source of antiosteoporosis agents.
\end{abstract}

Keywords: Anti-Osteoporosis, Osteoclastogenesis, Peperomia pellucida, Phytochemicals, Water Extract.

RASĀYAN J. Chem., Vol. 14, No.2, 2021

\section{INTRODUCTION}

Osteoporosis is a metabolic bone disorder, in which the rate of bone formation is lower than bone resorption, resulting from an imbalance of bone remodeling. Considering the geriatric population, osteoporosis represents an important major health problem. Osteoporosis causes over 8.9 million fractures globally every year, contributing to one osteoporotic fracture every three seconds. ${ }^{1}$

The current drug therapies for osteoporosis have been proven to reduce fracture risk and improve bone mineral density, but long-term administration has been correlated with many side effects. ${ }^{2,3}$ Also, the prophylactic agents for osteoporosis are still limited. Therefore, the search for new drugs is in progress. The plant is one of the alternative sources of medicines. Interest to develop herbal plants into treatment candidates for chronic diseases, such as osteoporosis, has been stimulated by current advancements in field of phytomedicine. ${ }^{4}$ 
RASĀYAN J. Chem.

Vol. 14 | No. 2 |1369-1377| April - June | 2021

Peperomia pellucida (草胡椒 căo hújiāo) or named as Toyakandha or Varshabhoo in Sanskrit is belongs to the family Piperaceae. This plant is often considered as an herb, wild, or weed. Traditionally, it has been used for many purposes, including bone fracture and arthritis. In Cameron, macerates or decoctions of this plant were administered orally or applied as a paste for treating a fracture. ${ }^{5}$ Ayurveda, the ancient Indian medical system, described it as -Rasa -Katu and Madhur; ViryaUshna; and Guna- Lakhu, rooksha, Teekshna. The whole of Peperomia plants is recommended as a medicinal herb. The fresh plant is eaten as a salad for treating gout and arthritis. ${ }^{6}$

The pharmacological activities of $P$. pellucida had been reported scientifically. ${ }^{5}$ One of its promising activities is an antiosteoporosis agent. Juice and two kinds of extracts from this plant have been tested for their antiosteoporosis effect. The administration of $P$. pellucida juice successfully prevents osteoporosis caused by ovariectomy procedures. The effect related to calcium homeostasis. ${ }^{7}$ Aqueous extract of this plant has been shown to accelerate bone healing, which could be due partly to the mineral content of the extract. ${ }^{8}$ Meanwhile, its ethanol extract showed a preventive effect on loss of bone mineralization and fracture healing in vivo. Also, even though the previous studies reported good fracture healing and osteoporosis-preventing effect of $P$. pelllucida extracts, there is no explanation about the contribution of phytochemical compounds based on the polarity.

This study aim was to assess the anti-osteoporosis effect of different polarity extracts of P. pellucida. The anti-osteoporosis effect was validated on osteoblasts proliferation and osteoclast differentiation in vitro. Furthermore, the possible active compounds of P.pellucida were identified through high-performance liquid chromatography with diode-array detector (HPLC-DAD) analysis compared with authentic standards. The results of this current study will provide important and useful information for the further development and application of $P$. pellucida.

\section{EXPERIMENTAL}

\section{Chemicals}

Peperomia pellucida, n-hexane, ethyl acetate, ethanol, aquadest (CV Fadillah, Bandung Kulon, Indonesia), acetone (Sigma Aldrich), Minimum Essential Medium Eagle-Alpha Modification (Alpha MEM) (Gibco), tetrazolium salt (Sigma Aldrich), Dulbecco's Modified Eagle Medium (DMEM) (Gibco), TRAP staining kit (Sigma Aldrich), penicillin, streptomycin, trypsin, Fetal Bovine Serum (Merck) and mouse receptor activator of NF-kappaB ligand (RANKL) was procured from Sigma Aldrich.

\section{Plant Materials Preparation}

A fresh plant of P. pellucida (L.) was harvested in Ciater and Cagak Region, West Java Province, Indonesia, in March and April 2016. The plant was authenticated at the Herbarium Bandungense, Institut Teknologi Bandung, Indonesia, with document number 705/I1.CO2.2/PL/2016 by a botanist. The whole fresh aerial parts of the plant were cleaned, cut into pieces and dried inside the oven at temperature 40$55^{\circ} \mathrm{C}$. The plants were extracted with, in order, n-hexane, ethyl acetate, and $96 \%$ ethanol using the sequential maceration method for $3 \times 24$ hours. The filtrate was collected and evaporated using a rotary evaporator. Water extract was prepared separately. The extraction was done by boiling $500 \mathrm{~g}$ of the powder in $8 \mathrm{~L}$ of aquadest for $3 \times 24$ hours. The mixture obtained was filtered, then was frozen at $-20{ }^{\circ} \mathrm{C}$ and freeze-dried to yield $11.20 \%(\mathrm{w} / \mathrm{w})$, which was stored at room temperature inside the desiccator until use.

\section{Cell Culture Condition}

UMR 106 (ATCC), a clonal line derived from rat osteosarcoma and murine macrophage RAW 264.7 (ATCC) cells were used in this research. These cells were maintained in continuous culture by the weekly passage in Alpha MEM and DMEM, high glucose, (Gibco, Invitrogen Corp.), respectively, supplemented with $1 \%$ penicillin/streptomycin and $10 \%$ FBS. The cells were incubated in a humidified atmosphere of $5 \% \mathrm{CO}_{2}$ in the air at $37^{\circ} \mathrm{C}$. The cells were subcultured every two or three days or until they reached $80 \%$ of confluency.

\section{Viability Assay and Proliferation Assay}

UMR-106 cells and RAW 264.7 cells were seeded in a 96-well plate (Corning) at $1.5 \times 10^{4}$ and $0.64 \times 10^{4}$ cells/well, respectively. After $3 \mathrm{~h}$ of incubation, the culture medium was removed. Then, the cells were 
RASĀYAN J. Chem.

Vol. 14 | No. 2 |1369-1377| April - June | 2021

treated with several concentrations of each P. pellucida extracts dissolved in dimethyl sulfoxide (DMSO) for 24 or $48 \mathrm{~h}$ following which cell viability and proliferation were determined by 3-(4,5-dimethylthiazol-2yl)-2,5-diphenyl tetrazolium bromide (MTT) assay. The DMSO final concentration was $0.1 \%$. After 2 days of incubation under conditions described above, MTT solution was added at concentration $0.5 \mathrm{mg} / \mathrm{mL}$ in fresh medium. The cells were incubated further for $4 \mathrm{~h}$ at $37^{\circ} \mathrm{C}$. The viable and activemetabolized cells will convert soluble MTT into an insoluble formazan reaction product in dark blue color. After 4 hours, DMSO was used to dissolve the formazan complex. The relative amount of viable cells was calculated by measuring the absorbance at $595 \mathrm{~nm}$ optical density with $655 \mathrm{~nm}$ as a reference wavelength with a microplate reader. Percentages of cell viability were calculated using the equation: \%viability $=(($ absorbance of the treatment group - absorbance of the blank $) /($ absorbance of the control group - absorbance of the blank) $* 100 \%$. Control experiments were undertaken using media only and $0.1 \%$ DMSO as the vehicle.

\section{RANKL-Induced Osteoclast Formation Assay}

RAW 264.7 cells which were in passage 14 were plated into 96-well plate at a density of $2 \times 10^{4}$ cells $/ \mathrm{cm}^{2}$ and cultured in DMEM, $1 \%$ penicillin/streptomycin, $10 \%$ FBS, and RANKL $(50 \mathrm{ng} / \mathrm{mL})$ with or without various concentrations of each P. pellucida extract dissolved in DMSO for five days. Every 2 days, the medium was changed. Multinucleated osteoclasts were observed after five days The cells were fixed and stained using TRAP staining kit according to the instructions from the manufacturer for tartrate-resistant acid phosphatase (TRAP) activity. TRAP-positive multinucleated osteoclasts containing $\geq 3$ nuclei were visualized and counted manually under an inverted microscope. The data were represented as the amount of TRAP-positive cells per well from three independent experiments in triplicate.

\section{High-Performance Liquid Chromatography Analysis}

HPLC was used to detect flavonoid compounds in the water extract. Each standard compound including apigenin, catechin, hyperoside, kaempferol, luteolin 7-O glucoside, luteolin, myricetin, naringenin, orientin, quercetine, and rutin was prepared at $500 \mathrm{ppm}$ while the extracts at $20000 \mathrm{ppm}$ in methanol. Twenty microliters of the samples were injected into the HPLC instrument. Column $(5 \mu \mathrm{m} ; 4.6 \times 250$ $\mathrm{mm}$, Kitenex) with diode-array detector was used in the separation process. In the process, a mobile phase which is consist of solvent $\mathrm{A}$ which is $0.05 \%$ trifluoroacetic acid and solvent $\mathrm{B}$ which is $0.038 \%$ trifluoroacetic acid in $83 \%$ acetonitrile $(\mathrm{v} / \mathrm{v})$ was used with the following gradient: $0-5$ min for $15 \% \mathrm{~B}$ in A, 5-10 min for $70 \%$ B in A, and 10-15 min for $70 \%$ B in A. The injection volume was $10 \mu \mathrm{L}$, and the flow rate was $1 \mathrm{~mL} / \mathrm{min}$. The detection was conducted at 280,350 , and $370 \mathrm{~nm}$. The standard compounds and the extracts were run for comparable detection and system optimization. They were injected separately, and then each detected compound by similar retention time was injected together with extract in adjusted concentration (extract at $400 \mu \mathrm{g} / \mathrm{mL}$ and compound at $100 \mu \mathrm{g} / \mathrm{mL}$ ) for confirming the result.

\section{Statistical Analysis}

SPSS software version 22.0 for Windows was used to analyze the data. Statistical analyses were performed by one-way analysis of variance accompanied by the Least Significant Difference test or Kruskal-Wallis test using Bonferroni adjustment. All values were expressed as mean value \pm standard deviation (SD).

\section{RESULTS AND DISCUSSION}

Bone remodeling event involves the role of osteoblast and osteoclast. For treating and preventing osteoporosis, not only the proliferation and activation of osteoblasts but also the formation and inactivation of osteoclasts are needed.

To investigate the effect of $P$. pellucida extracts on osteoblast proliferation, each $P$. pellucida extracts in the range $0.1-100 \mu \mathrm{g} / \mathrm{mL}$ was evaluated in an osteoblast cell line, UMR106 cells, using MTT assay at 48 hours post-treatment. The results were shown in Fig.-1A. Ethyl acetate and ethanol extract at concentration $0.1-10 \mathrm{ug} / \mathrm{mL}$ showed similar cell proliferation activity compared to control. N-hexane, ethyl acetate, and ethanol extract significantly decrease cell proliferation at $100 \mu \mathrm{g} / \mathrm{mL}$ while water extracts showed significant cell proliferation activity at a concentration of $0.1 \mathrm{ug} / \mathrm{mL}$ compared to control. 
RASĀYAN J. Chem.

To evaluate the effect of different $P$. pellucida extracts on osteoclastogenesis, the optimal dosage of each extract was first evaluated in RAW 264.7 cells using MTT assay at 48 hours post-treatment. The results were shown in Fig.-1B. At low concentrations $(0.1$ to $10 \mu \mathrm{g} / \mathrm{mL})$, n-hexane, ethyl acetate, and ethanol extracts showed similar cell viability compared to the control group while water extract exhibit a dosedependent increase of cell viability in comparison with the controls. At a high concentration $(100 \mu \mathrm{g} / \mathrm{mL})$, n-hexane and ethyl acetate significantly reduced cell viability below $80 \%$ whereas ethanol extracts significantly enhanced cell viability compared with control. Since concentrations at 0.1 to $10 \mu \mathrm{g} / \mathrm{mL}$ of all extracts are relatively nontoxic to RAW 264.7, the concentrations were further selected for the following experiments.
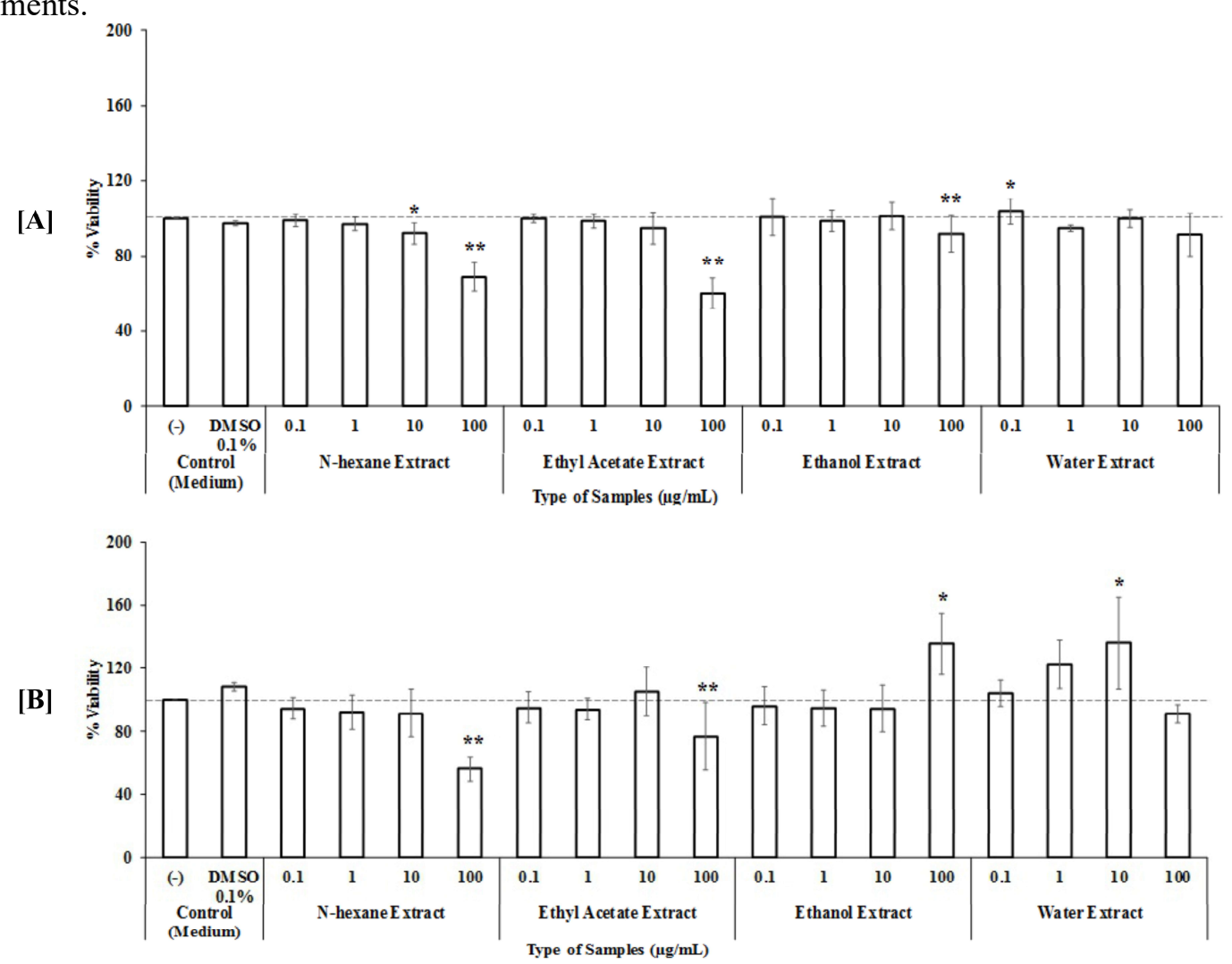

Fig.-1: Proliferation Activity and Cytotoxicity of $P$. pellucida Extracts. The proliferation activity and cytotoxicity of Peperomia pellucida were evaluated by MTT assay in UMR106 (A) and RAW 264.7 (B) cells respectively. Results are shown as percentage of cell viability (B) at $48 \mathrm{~h}$ after treatment. Error bar represent mean value \pm SD while * represent $\mathrm{p}$-value $<0.05$ and $* *$ represent $\mathrm{p}$-value $<0.01$. All statistics were assessed by comparison with the DMSO $0.1 \%$ control.

To investigate whether different $P$. pellucida extracts affect the osteoclastogenesis, RAW 264.7 cells were cultured with or without various concentration of each $P$. pellucida extracts in the presence of RANKL TRAP-positive multinuclear and giant cells, a typical morphology of osteoclasts were counted after 5 days treatment. N-hexane and ethyl acetate extracts demonstrated an increase of osteoclasts number in a dose-dependent manner as shown in Fig.-2. Ethanol extract increased the number of osteoclasts at low concentrations and the effect seems to decrease at higher concentrations. On contrary with other extracts, water extract showed a positive effect on osteoclastogenesis. The number of osteoclasts was decreased significantly by $92.45 \pm 1.82 \%$ when treated with water extract at concentration $10 \mu \mathrm{g} / \mathrm{mL}$ suggesting an inhibitory effect of water extract on osteoclastogenesis. Our data indicated that water extract of $P$. pellucida could effectively regulate osteoclastogenesis induced by RANKL on RAW 264.7 cells.

An interesting phenomena was found in this study. Water extract at concentration $100 \mu \mathrm{g} / \mathrm{mL}$ induced the morphology change of RAW 264.7 cells. The comparison between cell morphology of the control and water extract group can be seen in Fig.-3. Based on the figure, the cells treated with water extract had a 
RASĀYAN J. Chem.

Vol. 14 | No. 2 |1369-1377| April - June | 2021

bigger size and different form. However, there was no change in the number of nuclei. Even though there were morphology changes, the cells were metabolized active proved by MTT staining (Fig.-3B). Based on the morphology of the cells (Fig.-3), they tend to polarize into M1 macrophages.

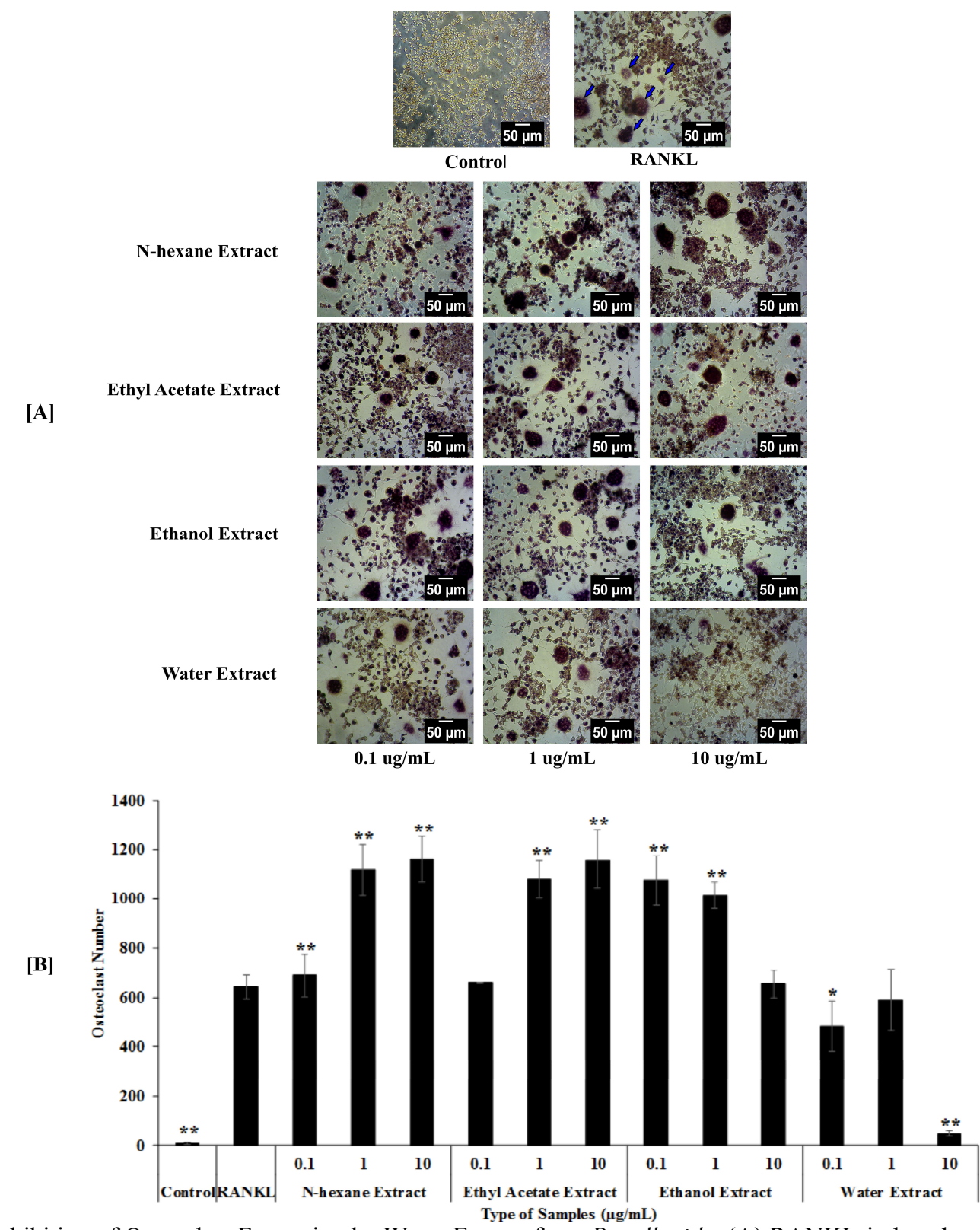

Fig.-2: Inhibition of Osteoclast Formation by Water Extract from $P$. pellucida. (A) RANKL-induced osteoclast with

TRAP staining (magnification: 20x; the blue arrows pointed osteoclasts); (B) Amount of osteoclasts in each test groups. * represent $\mathrm{p}$-value $<0.05$ and ** represent $\mathrm{p}$-value $<0.01$ versus RANKL group.

Several studies had been described the M1 macrophages. ${ }^{9-12}$ Macrophage polarization was also reported can be induced by natural products besides its pathological inducers (i.e LPS, IFN- $\gamma$ and TNF- $\alpha$ ) ${ }^{13}$ M1 macrophage is well known as killer cells or proinflammatory macrophages which is exhibits phagocytic activity. In contrast with M2 macrophage, M1 macrophage can secrete pro-inflammatory cytokines including IL-1 $\beta$, IL-6, IL-10, IL-12, IL-18, IL-23, TNF- $\alpha$, type I IFN, IFN- $\gamma$, and TGF- $\beta,{ }^{14,15}$ also produces nitric oxide. This form involves the pathology of inflammation-related diseases. It also shows an important part in other conditions, including immune responses and bone remodeling. ${ }^{15,16}$ 
RASĀYAN J. Chem.

Vol. 14 | No. 2 |1369-1377| April - June | 2021

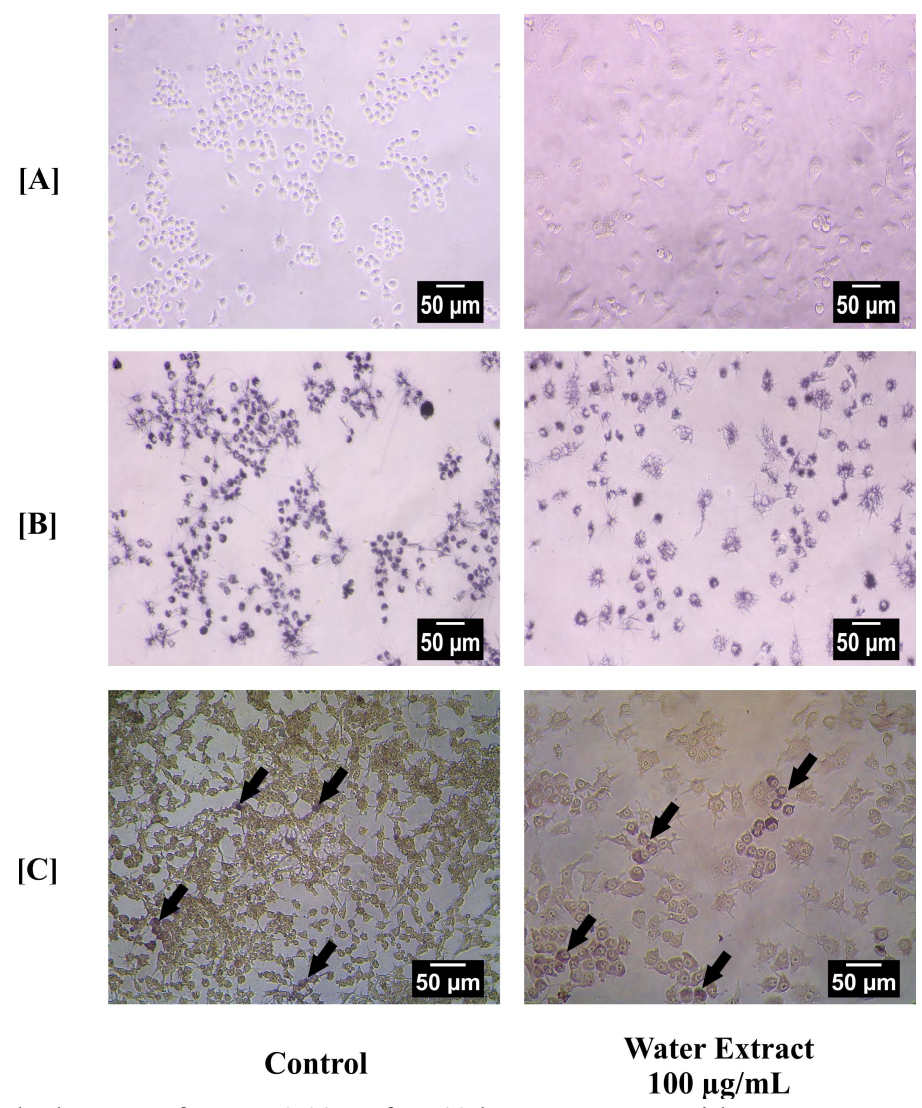

Fig.-3: Morphological Changes of RAW 264.7 after 48 hrs Treatment with Water Extract from P. pellucida at Concentration of $100 \mu \mathrm{g} / \mathrm{mL}$. RAW264.7 cells were cultured with $0.1 \%$ DMSO as control or water extract from $P$. pellucida for $48 \mathrm{hrs}$. The morphology of cells was observed using an inverted microscope. (A) Unstrained RAW 264.7 cells, (B) MTT staining, (C) TRAP staining. Magnification: 20x, scale bar $50 \mu \mathrm{M}$. The black arrows represent TRAP-positive cells.

The water-soluble or high polarity compounds seem to have a major role in the anti-osteoporosis activity of $P$. pellucida extract. Water-soluble compounds are important in osteoporosis treatment as the compounds that were reported might have a strong estrogenic effect. ${ }^{17}$ The estrogenic effect is known can reduce bone turnover. Estrogen inhibits bone resorption by blocking the formation of new osteoclasts as its dominant acute effect both directly and indirectly. Also, estrogen can modulate RANK signaling in

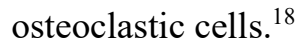

As water-soluble compounds have a good effect on treating osteoporosis, water extract is the selected preparation for daily use. The result of this study supporting its development in folk medicine. Traditionally, $P$. pellucida only serves as salad and macerate or decocta with water as a solvent. ${ }^{5}$

This study suggests the mechanism of action of water extract is through its capability to induce macrophage polarization into M1 form, as depicted in Fig.-3, which is in line with the previous study. ${ }^{15}$ In osteoporosis condition, M1 macrophages were found can inhibit osteoclastogenesis primarily because of secreted IFN- $\gamma$. IFN- $\gamma$ inhibited gene expression of NFATc1 which is a master regulator of osteoclastogenesis, IL-12, which is also secreted by M1 macrophage, contributes to decreasing the number of osteoclasts. IL-12 effect mediated through upregulation of mRNA for caspase-3 which is important for apoptosis, and the number of apoptotic cells in the RANKL-induced osteoclasts. ${ }^{15} \mathrm{IL}-10$, which is secreted higher by M1 than M0 and M2, also has a positive effect on bone. It is important in the regulation of osteoblastic bone formation and the inhibition of osteoclastic bone resorption. However, it was not associated with the inhibition of osteoclastogenesis by M1 macrophages. ${ }^{15,19,20}$

M1 (inflammatory) macrophages, originally, were hypothesized to promote osteoclastogenesis because of the production of TNF- $\alpha$. However, the results from the previous and this recent study have, in contrast, revealed that M1 macrophages can suppress osteoclastogenesis, even while producing TNF- $\alpha$. IFN- $\gamma$ and 
RASĀYAN J. Chem.

Vol. 14 | No. 2 |1369-1377| April - June | 2021

IL-12, which is mediate the inhibitory effects, were confirmed can override the influence of TNF- $\alpha$. The previous study suggested that the signaling of IFN- $\gamma$-derived cell acts upstream of TNF- $\alpha$ 's target, including a critical signaling molecule, TRAF6, which can inhibit the activation of the transcription factor JNK and NF-kB by RANKL, thus nullifying its signal. ${ }^{15,21}$

Many natural products can regulate the activation of macrophage polarization. Regulating macrophage polarization has been a key role of some natural compounds to exert their activity. ${ }^{13}$ Luteolin act to inhibit inflammation by alteration of M1/M2 macrophages. ${ }^{22}$ Celastrol was also reported can suppressinflammatory M1 macrophage polarization that contributes to its anti-obesity effect. ${ }^{23}$ The increase of M1 macrophage polarization, as observed in this study, was also reported caused by Lycium barbarum. ${ }^{24}$

Finally, HPLC analysis was conducted to determine the phytochemical profile of water extract., as this extract showed the strongest activity. Using the analysis system as described above, only apigenin was detected. The peak of apigenin appeared after 6 min of running time (Fig.-4).

$[\mathrm{A}]$

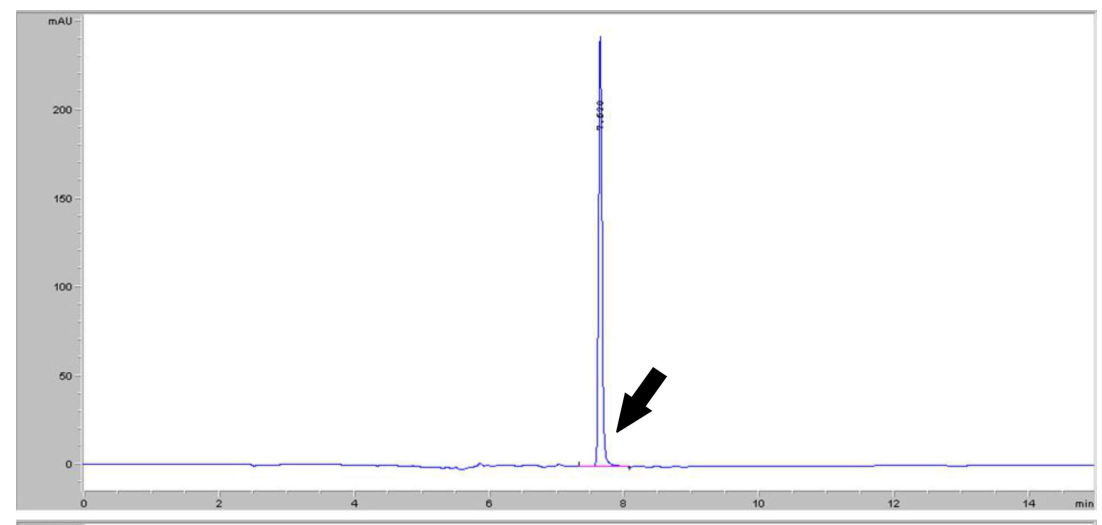

[B]

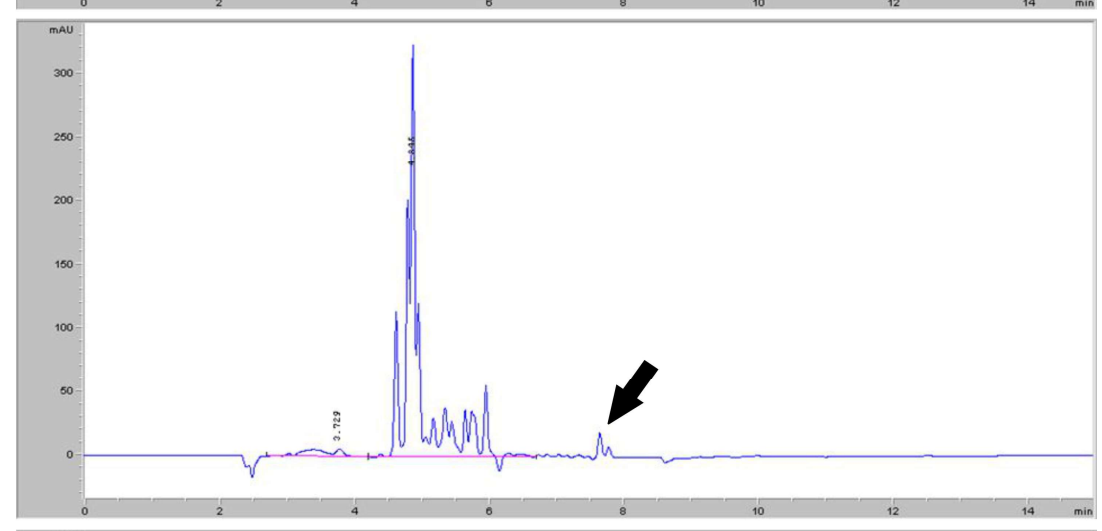

$[\mathrm{C}]$

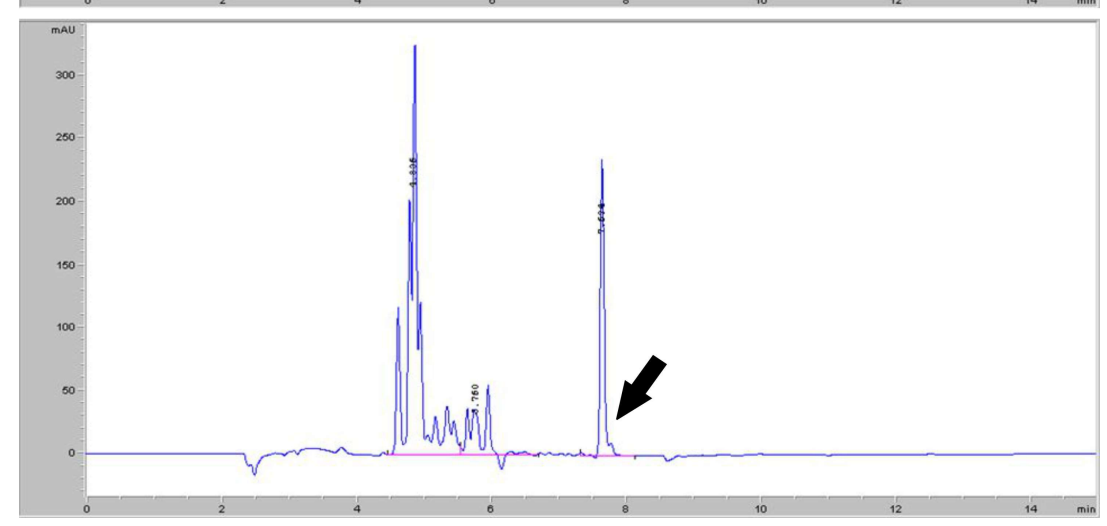

Fig.-4: Detection of Apigenin in Water Extract of P. pellucida using HPLC. (A) the spectrum of Apigenin 100 ppm; (B) spectrum of water extract $400 \mathrm{ppm}$; and (C) spectrum of apigenin in combination with water extract. The black arrows pointed the peak of apigenin. 
The detection of apigenin specifically in water extract of P. pellucida was the first time in this study. The finding supports the previous study that had revealed water extract of $P$. pellucida contains phenolics group of compounds besides steroids and alkaloids. ${ }^{25}$ Phenolic group of compounds are commonly founded in water extract or high polarity extract as reported in other studies. ${ }^{26-28}$

Apigenin was predicted as one of the active compounds in the water extract of P. pellucida. Previous studies have revealed its inhibition effect on osteoclasts formation and function in vitro. ${ }^{29,30}$ It also can induce apoptosis of mature osteoclasts. ${ }^{30}$ Even though it promotes the inhibition of osteoblast differentiation and proliferation in vitro, in vivo experiment successfully demonstrated that can prevent trabecular bone loss. ${ }^{29}$

\section{CONCLUSION}

In summary, the most polar extract exhibited the safest toward osteoblast cells and macrophage-like cells. This extract has a strong effect to inhibit osteoclasts formation induced by RANKL. The suggested mechanism of action is the induction of M1 macrophage polarization.

\section{ACKNOWLEDGEMENT}

This study was financially supported by the Ministry of Research, Technology and Higher Education of the Republic of Indonesia. The authors also would like to express gratitude to the Institute of Molecular Biosciences and Center of Calcium and Bone Research, Faculty of Science, Mahidol University, Thailand, which provided technical help and cell culture facilities.

\section{REFERENCES}

1. O. Johnell and J.A. Kanis, Osteoporosis International, 17(12), 1726(2006), DOI:10.1007/s00198006-0172-4

2. F.S. Hough, S.L. Brown, B. Cassim, M.R. Davey, W. de Lange, T.J. de Villiers, G.C. Ellis, S. Lipschitz, M. Lukhele and J.M. Pettifor, South African Medical Journal, 104(4), 279(2014), DOI: $10.7196 /$ samj. 7505

3. C. Deal, Nature Clinical Practice Rheumatology, 5(1), 20(2009), DOI:10.1038/ncprheum0977

4. J.J. Jolly, K.-Y. Chin, E. Alias, K.H. Chua and I.N. Soelaiman, International Journal of Environmental Research and Public Health, 15(5), 963(2018), DOI:10.3390/ijerph15050963

5. I.G.A.A. Kartika, M. Insanu, D. Safitri, C.A. Putri and I.K. Adnyana, Pharmacology Online, 2016(2), 30(2016).

6. P. Majumder, Journal of Pharmaceutical and Scientific Innovation, 1(6), 7(2012).

7. C.A. Putri, A. Kartika and I.K. Adnyana, Journal of Chinese Pharmaceutical Sciences, 25(7), 546(2016), DOI: 10.5246/jcps.2016.07.060

8. N.T. Florence, S.T.S. Huguette, D.J. Hubert, G.K. Raceline, D.D.P. Desire, K. Pierre and D. Theophile, BMC Complementary and Alternative Medicine, 17, 188(2017), DOI:10.1186/s12906017-1686-3

9. K.Y. Lee, Journal of Medical and Biological Engineering, 2(1), 1(2019), DOI:10.30579/mbse.2019.2.1.1

10. https://www.bio-rad-antibodies.com/macrophage-polarization-minireview.html

11. F.Y. McWhorter, T. Wang, P. Nguyen, T. Chung and W.F. Liu, In Proceedings of the National Academy of Sciences, United States of America, pp. 17253-17258 (2013), DOI: $10.1073 /$ pnas. 1308887110

12. B. Rinsky, S. Hagbi-Levi, S. Elbaz-Hayoun, M. Grunin and I. Chowers, Molecular Vision, 23, 889(2017).

13. A. Davoodvandi, R. Sahebnasagh, O. Mardanshah, Z. Asemi, M. Nejati, M.K. Shahrzad, H.R. Mirzaei and H. Mirzaei, Current Pharmaceutical Design, 25(30), 3228(2019), DOI: $10.2174 / 1381612825666190829154934$

14. C. Atri, F.Z. Guerfali and D. Laouini, International Journal of Molecular Sciences, 19(6), 1801 (2018), DOI:10.3390/ijms19061801

15. T. Yamaguchi, A. Movila, S. Kataoka, W. Wisitrasameewong, M. Ruiz Torruella, M. Murakoshi, S. Murakami and T. Kawai, Infection and Immunity, 84(10), 2802(2016), DOI:10.1128/IAI.00461-16

16. K. Ley, The Journal of Immunology, 199(7), 2191(2017), DOI:10.4049/jimmunol.1701135 
RASĀYAN J. Chem.

Vol. 14 | No. 2 |1369-1377| April - June | 2021

17. N. Creusot, H. Budzinski, P. Balaguer, S. Kinani, J. M. Porcher and S. Aït-Aïssa, Analytical and Bioanalytical Chemistry, 405(8), 2553(2013), DOI:10.1007/s00216-013-6708-5

18. T. Okman-Kilic, 2015, Estrogen Deficiency and Osteoporosis, Advances in Osteoporosis, InTechOpen Limited, London, pp. 7-18, DOI:10.5772/59407

19. P. Pietschmann, D. Mechtcheriakova, A. Meshcheryakova, U. Foger-Samwald and I. Ellinger, Gerontology, 62(2), 1(2016), DOI:10.1159/000431091

20. Q. Zhang, B. Chen, F. Yan, J. Guo, X. Zhu, S. Ma and W. Yang, BioMed Research International, 2014(1), 1(2014), DOI: $10.1155 / 2014 / 284836$

21. H. Takayanagi, K. Ogasawara, S. Hida, T. Chiba, S. Murata, K. Sato, A. Takaoka, T. Yokochi, H. Oda, K. Tanaka, K. Nakamura and T. Taniguchi, Nature, 408(6812), 600(2000), DOI: $10.1038 / 35046102$

22. S. Wang, M. Cao, S. Xu, J. Shi, X. Mao, X. Yao and C. Liu, Inflammation, 43(1), 1(2020), DOI: 10.1007/S10753-019-01099-7

23. D. Luo, Y. Guo, Y. Cheng, J. Zhao, Y. Wang and J. Rong, Aging, 9(10), 2069(2017), DOI: 10.18632/aging.101302

24. Y.K. Zhang, J. Wang, L. Liu, R.C.-C. Chang, K.-F. So and G. Ju, BMC Complementery and Alternative Medicine, 13(67), 1(2013), DOI:10.1186/1472-6882-13-67

25. V. Kalaiarasi, M. Johnson, N. Janakiraman and A. Sivaraman, International Journal of Pharmaceutical Sciences and Research, 1(1), 4(2016).

26. S. Yani, E. Y. Sukandar, M. Insanu, and N. F. Kurniati, Rasayan Journal of Chemistry, 13(3), 1807(2020), DOI: 10.31788/RJC.2020.1335843

27. D. Jenifer and B. R. Malathy, Rasayan Journal of Chemistry, 12(2), 630(2019), DOI: $10.31788 /$ RJC.2019.1225134

28. S. Fatema, M. Farooqui, M. Ubale, and M.A.A.K. Pathan, Rasayan Journal of Chemistry, 12(2), 616(2019), DOI: 10.31788/RJC.2019.1222065

29. T. Goto, K. Hagiwara, N. Shirai, K. Yoshida and H. Hagiwara, Cytotechnology, 67(2), 357(2015), DOI: 10.1007/s10616-014-9694-3

30. S. Bandyopadhyay, J-M. Lion, R. Mentaverri, R. Mentaverri, D.A. Ricupero, S. Kamel, J.R. Romero and N. Chattopadhyay, Biochemical Pharmacology, 72(2), 184(2006), DOI: $10.1016 / j . b c p .2006 .04 .018$

[RJC-6073/2020] 